\title{
Transpancreatic precut papillotomy versus double-guidewire technique in difficult biliary cannulation: a systematic review and meta-analysis
}

\section{(ㄷ)(1) $(-)$}

\author{
Authors \\ Institutions \\ 1 Gastroenterology Unit of Hospital Nacional Edgardo \\ Rebagliati Martins, Lima, Peru \\ 2 Universidad Peruana de Ciencias Aplicadas (UPC) \\ 3 Gastroenterology Unit of Angloamericana Clinic - Lima, \\ Perú \\ 4 Gastroenterology Unit of Hospital General Universitario \\ de Alicante, Alicante, Spain
}

Edson Guzmán-Calderón 1,2,3, Belen Martinez-Moreno ${ }^{4}$, Juan A. Casellas ${ }^{4}$, José Ramón Aparicio ${ }^{4}$

submitted 13.1.2021

accepted after revision 16.6 .2021

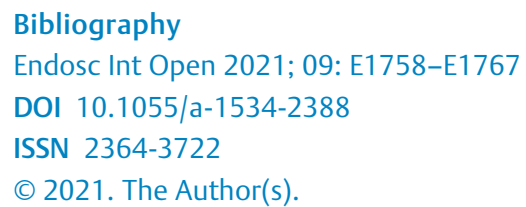
Commons Attribution-NonDerivative-NonCommercial License, permitting copying and reproduction so long as the original work is given appropriate credit. Contents may not be used for commercial purposes, or adapted, remixed, transformed or built upon. (https://creativecommons.org/licenses/by-nc-nd/4.0/)

Georg Thieme Verlag KG, Rüdigerstraße 14,

70469 Stuttgart, Germany

Corresponding author

Gerly Edson Guzmán Calderon, Av. Edgardo Rebagliati s/n Jesús María, Lima, Perú

edson_guzman@hotmail.com

\section{ABSTRACT}

Background and study aims Approximately $11 \%$ of biliary cannulations are considered difficult. The double guidewire (DGW-T) and transpancreatic sphincterotomy (TPS) are two useful techniques when difficult cannulation exists and the main pancreatic duct is unintentionally accessed. We carried out a systematic review and meta-analysis to evaluate the effectiveness and security of both DGW-T and TPS techniques in difficult biliary cannulation.

Methods We conducted a systematic review in different databases, such as PubMed, OVID, Medline, and Cochrane Databases. Were included all RCT which showed a comparison between TPS and DGW in difficult biliary cannulation. Endpoints computed were successful cannulation rate, median cannulation time, and adverse events rate.

Results Four studies were selected (4 RCTs). These studies included 260 patients. The mean age was $64.79 \pm 12.99$ years. Of the patients, $53.6 \%$ were men and $46.4 \%$ were women. The rate of successful cannulation was $93.3 \%$ in the TPS group and $79.4 \%$ in the DGW-T group $(P=0.420)$. The rate of post-endoscopic retrograde cholangiopancreatography pancreatitis (PEP) was lower in patients who had undergone TPS than DGW-T (TPS: $8.9 \%$ vs DGW-T: $22.2 \%$, $P=0.02)$. The mean cannulation time was $14.7 \pm 9.4 \mathrm{~min}$ in the TPS group and $15.1 \pm 7.4$ min with DGW-T $(P=0.349)$. Conclusions TPS and DGW are two useful techniques in patients with difficult cannulation. They both have a high rate of successful cannulation; however, the PEP was higher with DGW-T than with TPS.

\section{Introduction}

Endoscopic retrograde cholangiopancreatography (ERCP) is an endoscopic technique used to diagnose and treat biliopancreatic diseases. Selective cannulation of the common bile duct is necessary to achieve clearance. Approximately $11 \%$ of biliary cannulations are considered difficult [1]. Difficult biliary cannulation has diverse definitions. European Society of Gastrointestinal Endoscopy (ESGE) guidelines [2] define difficult cannulation as more than five cannulation attempts, more than 5 min- utes trying to cannulate with visualization of the papilla, or more than one involuntary cannulation or opacification of the Wirsung duct. On the other hand, American guidelines [3] define it as the impossibility of realize biliary cannulation after attempting it for more than 10 minutes.

When cannulation is difficult, there is the possibility of unintentionally accessing the main pancreatic duct, which increases the risk of post-ERCP pancreatitis (PEP) [4]. In these cases, other techniques are necessary to achieve biliary access. First, the double guidewire technique (DGW-T) consists of keeping the 
guidewire inserted in the main pancreatic duct to straighten the common duct (biliary and pancreatic) and it helps to orient the common bile duct (CBD) axis and facilitate biliary cannulation by inserting a second guidewire [5-8]. And the other hand, the transpancreatic sphincterotomy technique (TPS) consists of passing a sphincterotome over the guidewire previously inserted in the main pancreatic duct and performing a septotomy in the direction of the CBD (11-12-o'clock position) [2, 9-11].

We carried out a systematic review and meta-analysis to evaluate and to compare the effectiveness and safety of both DGW-T and TPS for difficult biliary cannulation.

\section{Methods}

\section{Literature search and data selection criteria}

We conducted a systematic review of different databases, such as PubMed, Cochrane, Medline, and OVID. A search was made of all studies published until November 2020. Only English-language studies were considered. The following terms were searched using Boolean operators: "transpancreatic precut", OR "transpancreatic sphincterotomy" OR "transpancreatic septotomy" OR "transpancreatic sphincterotomy" AND "double guidewire" OR “double guidewire technique" AND "difficult biliary cannulation."

We excluded publications that involved individual studies (e.g., only DGW-T studies or only TPS studies). We excluded studies that compared both techniques with other precut techniques (e.g., fistulotomy or conventional precut). Only studies that compared DGW-T with TPS in the English language were included. Review articles, other meta-analyses, case reports, duplicates, redundant data, book chapters, editorials, commentaries, non-relevant publications, and incomplete analyses were excluded from the pooled-data analysis ( $\triangleright$ Fig. 1 ). All reviewers fully agreed with the selection and analysis of the studies.

\section{Statistic methods ana data analysis}

\section{Endpoints}

The primary endpoints computed were successful cannulation rate, median cannulation time, and rate of adverse events (AEs) (principally post-ERCP pancreatitis for TPS and DGW-T. Successful cannulation was defined as successful insertion of the guidewire or sphincterotome into the common bile duct (CBD) after DGW-T or TPS. Cannulation time was defined as the time it takes to access the CBD with either of the two techniques. AEs were defined as complications related to the endoscopic procedure. Post-ERCP pancreatitis (PEP) was defined as the presence of abdominal pain plus elevation of the serum amylase and/or lipase level by at least three times the upper limit of normal at about 24 hours after the endoscopic procedure.

\section{Data extraction}

To confirm study eligibility, we reviewed the full text of selected articles. To extract the data selected, we design a table for data extraction from each study. The main variables selected were: author and year of publication, country, study design, age and

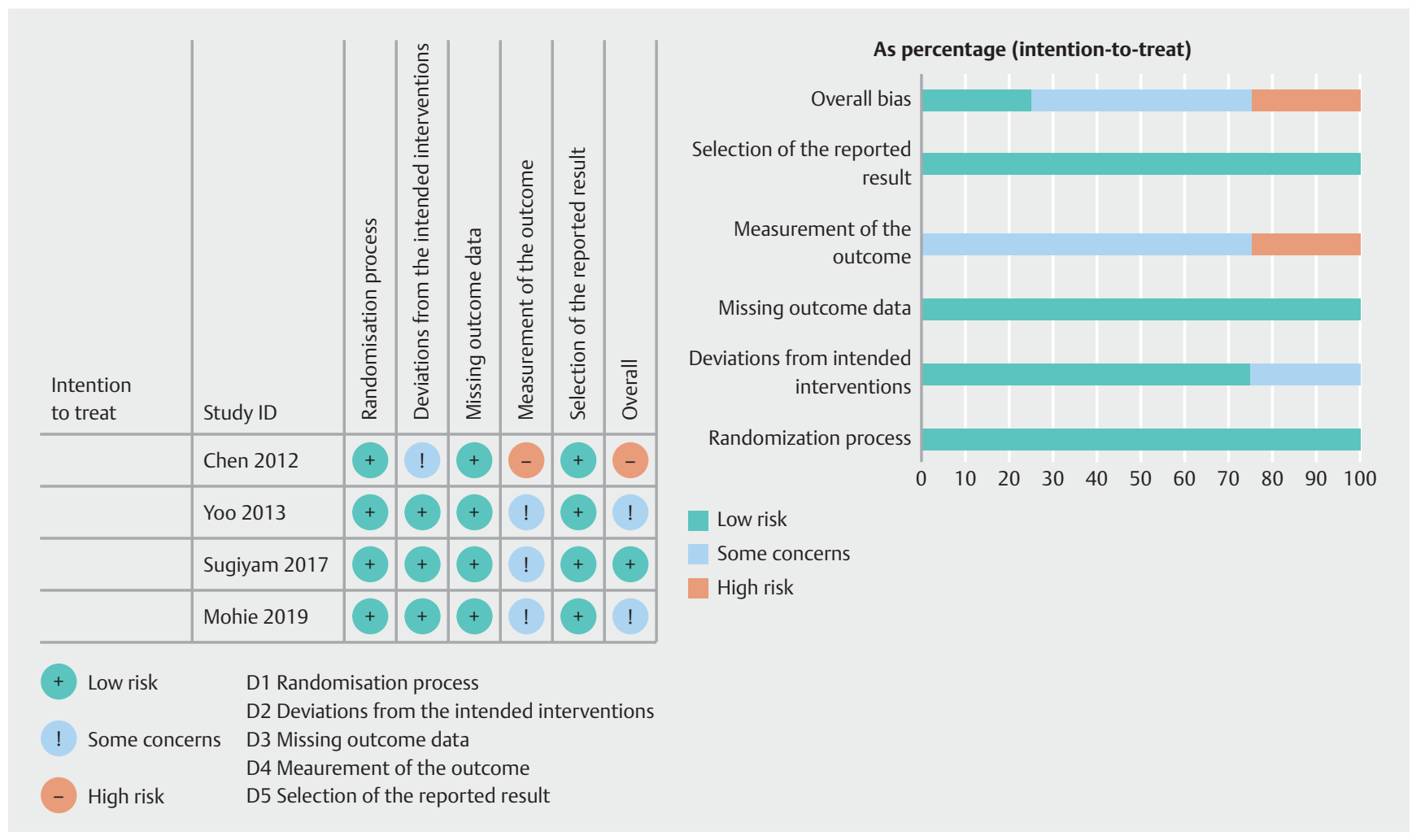

- Fig. 1 Risk of bias. 
sex of patients, number of patients, distribution of patients in each group (TPS and DGW-T), indication for ERCP, rate of successful cannulation, mean cannulation time in each study, and rate of AEs for each technique, principally the PEP rate in each group.

\section{Statistical data analysis}

Descriptive statistics are presented as percentages (\%). For the analysis of categorical variables, mean and standard deviations (SDs) were calculated, and in the case of the continuous variable, interquartile range was analyzed. The endpoints (rate of successful cannulation, mean cannulation time, PEP rate, and overall AE rate) were presented as percentages and $95 \%$ confidence intervals (Cls). The Greenwood method was used. For data analysis, we used Statistical software Stata version 15.1. This meta-analysis was performed by calculating the risk ratio (RR) and standard error (SE) in each study. A funnel plot for each endpoint was drawn. An Egger test was used to determine the publication bias quantitatively, whereas visual analysis of the funnel plot was used to determine it qualitatively [12]. We also used the fail-safe $\mathrm{N}$ test and Duval and Tweedie's "Trim and Fill" test to evaluate the impact of bias [13]. To assess heterogeneity, we used the $\mathrm{I}^{2}$ statistic and heterogeneity statistic $\mathrm{Q}$. If the $I^{2}$ statistic was more than $50 \%$ or the $P$ value of the $Q$ test was $<0.05$, we used the random-effect model.

We planned to analyze dichotomous outcomes (successful cannulation rate, adverse events rate) as a risk ratio (RR) with a $95 \% \mathrm{Cl}$. We planed to analyze continuous outcomes (mean cannulation time) with a $95 \% \mathrm{Cl}$.

The results were considered statistically significant at the $P<$ 0.050 level if the $95 \% \mathrm{Cl}$ did not include 1.00 . A random-effects model was used regardless of heterogeneity. We used the $\mathrm{I}^{2}$ statistic to measure heterogeneity among the trials in each analysis. If we had identified substantial heterogeneity, as per the Cochrane Handbook for Systematic Reviews of Interventions (>50\% to $60 \%$ ), we planned to explore it by prespecified subgroup analysis. We also assessed heterogeneity by evaluating whether there was a good overlap of $\mathrm{Cl}$.

We planned to use Egger's test to determine the statistical significance of the reporting bias [12]. We planned to consider $P<0.05$ to be statistically significant reporting bias.

We performed the analysis using Stata version 15.1. We used the Mantel-Haenszel method for dichotomous data [13].

\section{Sensitivity analysis}

We planned to perform the following sensitivity analyses defined a priori to assess the robustness of our conclusions:

1. Excluding trials at unclear or high risk of bias (one or more of the 'Risk of bias' domains (other than blinding of the surgeon) classified as unclear or high).

2. Excluding trials in which either the mean or standard deviation, or both, were attributed.

The risk of bias was analyzed using the RoB2: A revised Cochrane risk of bias tool for randomized trials. This tool was used for all four individual studies ( $\mathbf{F i g . 1}$ )

\section{GRADE analysis}

GRADE profiler software was used to assess the quality of evidence and reliability of this meta-analysis. Detailed information on this analysis is shown in $>$ Table $\mathbf{1}$.

\section{Results}

\section{Characteristics of included studies}

Assessment of the risk of bias using the Cochrane Collaboration tool is presented in $\mathbf{F i g . 1 . ~} \mathbf{F i g .} \mathbf{2}$ is a flow diagram the search and selection process. The initial search yielded a total of 147 articles, of which we selected and analyzed four studies [1417]. All studies are randomized controlled trials (RCTs), but one of them was published as an abstract [14]. Two of the four studies were conducted in South Korea $[14,15]$, one in Japan [16], and one in Egypt [17]. The studies were published from 2012 to 2020 . Huang et al. [18] published a retrospective study with a larger number of patients, but this was excluded by design to avoid bias.

\section{Demographic features}

- Table 2 lists the features and distribution of the four included studies [14-17], which included a total of 260 patients. The mean age was $64.79 \pm 12.99$ years; this value was only possible to analyze in three of the four studies (Chan et al.,[14] did not enter these data in their abstract). Of 179 patients, $53.6 \%$ were men (93 patients), and $46.4 \%$ were women ( 83 patients). One hundred thirty-four patients (51.5\%) underwent ERCP with the TPS technique and 126 (48.5\%) underwent ERCP with DGW-T. ERCP indications in the different studies were mostly benign etiology (59.7\%); malignant causes were the indication in $32.5 \%$ and indeterminate causes in $7.8 \%$. The most frequent benign ERCP indication in both study groups was choledocholithiasis in $37.4 \%$, while the most frequent malign ERCP indication was pancreatic cancer in $15.6 \%$.

\section{TPS vs. DGW-T}

All four studies compared head-to-head successful cannulation, overall $A E$, and PEP rates and mean cannulation time. The successful cannulations was similar in both groups, (TPS: $93.3 \%$ vs. DGW-T: $79.4 \%, R R=1.09,95 \% \mathrm{Cl}$ [0.90-1.32]). Heterogeneity was not found in the pooled technical success analysis, $I^{2}=0 \%$ (>Fig.3).

The mean cannulation time in each group was analyzed and was similar in both groups. In the TPS group, the mean cannulation time was $14.7 \pm 9.4$ minutesw, whereas the mean in the DGW-T group was $15.1 \pm 7.4$ minutes, SMD $=0.121,95 \%$ $\mathrm{Cl}[-0.13-0.37]$, the heterogeneity was present $\mathrm{I}^{2}=92 \%$ ( Fig.4).

\section{Post-ERCP pancreatitis rate and other adverse events}

During the analysis of AEs, we observed that both groups had a similar total complication rate (TPS: $24.8 \%$ vs DGW-T: $37.4 \%$, $\mathrm{RR}=0.76,95 \% \mathrm{Cl}[0.50-1.15])$, heterogeneity was not found, $\mathrm{I}^{2}=0 \%$ ( Fig. 5 ). 


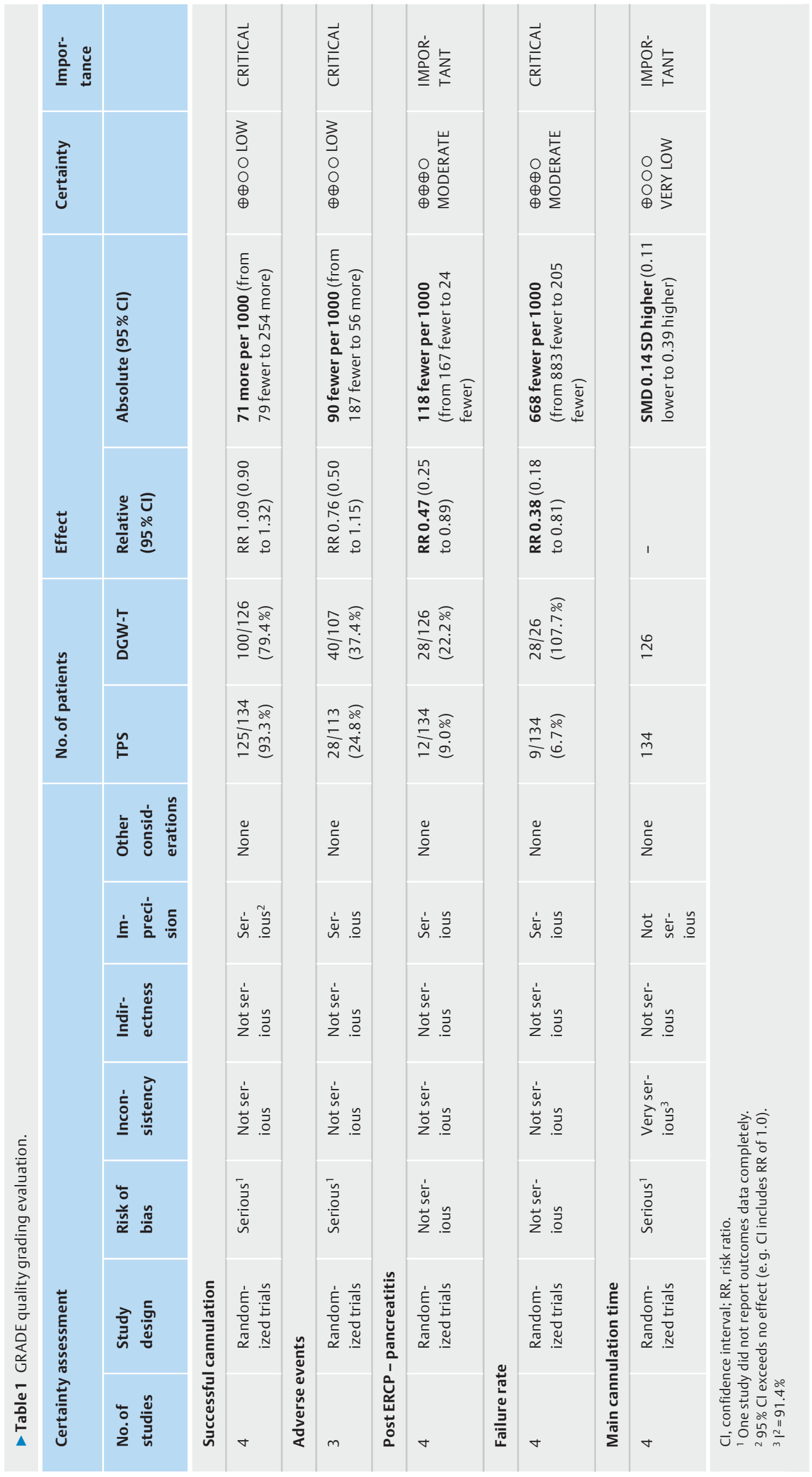


"Transpancreatic precut", or "transpancreatic sphincterotomy" or "transpancreatic septotomy" or "transpancreatic sphincterotomy" and "double guidewire" or "double guidewire technique" and "difficult biliary cannulation"

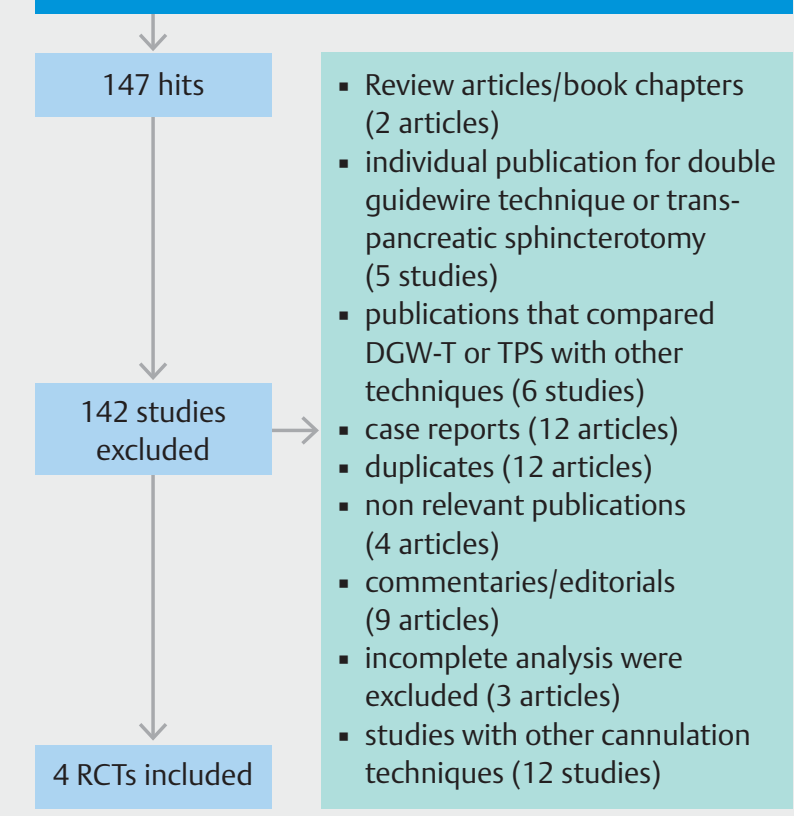

Fig. 2 Studies identified in the literature.

We specifically analyzed the PEP rate and found that the patients who underwent TPS technique had a lower PEP rate than patients who underwent DGW-T (TPS: $8.9 \%$ vs DGW-T: $22.2 \%$, $P=0.020, R R=0.47,95 \% \mathrm{Cl}[0.25-0.89])$, heterogeneity was not found, $\mathrm{I}^{2}=0 \%$ ( Fig. 6 ).

\section{Discussion}

ERCP continues to be the first-line technique for accessing the CBD; however, accessing it is not always possible due to anatomical alterations, presence of peripapillary diverticula, or postsurgical alterations. For these reasons, there are alternative techniques, such as TPS and DGW-T, to increase cannulation success. Our searcfh found no meta-analysis that included the four RCTs $[14,15,17,18]$ and would facilitate a comparative analysis between these two techniques. TPS is generally believed to have a higher rate of PEP, as the technique can produce more significant trauma to the pancreas than DGW-T. Our meta-analysis shows that the previous hypothesis is true because the difference found in our study was statistically significant.

Our study found that the successful cannulation rate with the TPS technique was statistically similar in both groups. Theoretically, access to the CBD with TPS is easier because performing an adequate sphincterotomy facilitates better visualization of the access, whereas that does not occur in patients undergoing DGW-T. However, for some authors, there is a high rate of cannulation with DGW-T. For example, Maeda et al. [19] performed an RCT in 2003 and reported a successful cannulation rate of $93 \%$, supported by the fact that straightening of the papilla with the guidewire previously introduced in the main pancreatic duct facilitated future cannulation of the CBD.

This systematic review showed that patients undergoing DGW-T have a PEP rate of $22.2 \%$, which is higher than for TPS (8.9\%). Some studies, such as a multicenter RCT carried out by Herreros de Tejada [20] published in 2009, found a high PEP rate after performing DGW-T (17\%) and the successful cannulation rate was no higher than woith the standard cannulation technique ( $47 \%$ vs $56 \%$ respectively). On the other hand, in Peru, a study was carried out in which it was observed that the PEP rate with DGW-T was $8.3 \%$ [21]. In this context, one of the great fears with the TPS technique was that some studies showed a higher complication rate than with standard cannulation. Akashi et al. [22] published a study in which the complication rate was $9.9 \%$, which was significantly higher than the complication rate with the conventional technique, which was $0.8 \%(P<0.001)$. However, a study published by Kahaleh et al. [23] reported that the PEP rate with TPS was $8 \%$, similar to that with standard cannulation. The higher PEP rate in patients undergoing DGW-T may also be justified by the longer procedure time. This systematic review demonstrated that the mean cannulation time in patients undergoing DGW-T is similar in both groups (TPS: $14.7 \pm 9.4 \mathrm{~min}$ vs DGW-T: $15.1 \pm 7.4 \mathrm{~min}$ ).

It is interesting to analyze each study independently concerning the PEP rate because, in the study by Sugiyama et al. [17], prophylactic pancreatic stenting was used in all cases for prevention of PEP. This fact may reflect the low PEP rate in this study $(2.9 \%$ in both groups, TPS and DGW-T). In the studies of Yoo et al. [14] and Mohie et al. [18], prophylactic pancreatic stenting was not used in any case. The study by Chan et al. [13] does not mention this fact, nor does the retrospective study by Huang et al. [16]. However, the number of patients in whom prophylactic pancreatic stent was placed is not mentioned. The authors report only that it was placed when the main pancreatic duct cannulation was greater than five times.

The use of pharmacological prophylaxis for PEP prevention with indomethacin or diclofenac has not been considered in any study. We believe that hyperamylasemia without abdominal pain is not necessarily a complication that involves clinical deterioration in patients. For this reason, we did not include this variable in our analysis.

One advantage of this systematic review is that it is mainly made up of RCT. We decided to consider the study published by Cha et al.[13]. Although it was published as an abstract, it describes the primary endpoints we evaluated in our meta-analysis. Second, it was the first meta-analysis designed mainly to compare "head-to-head" these two techniques and studies in which the procedures were sequential (one after the other) are excluded. Our meta-analysis does have limitations. First, the definition of "difficult cannulation" is not usually homogeneous in the different studies. However, we believe this difference is not relevant because the statistical results showed a heterogeneity rate of $0 \%$, mainly for successful cannulation 


\begin{tabular}{|c|c|c|c|}
\hline 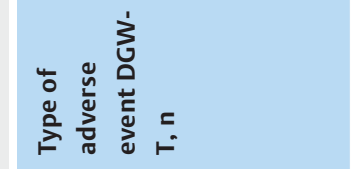 & 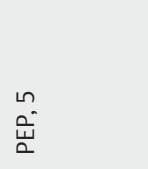 & 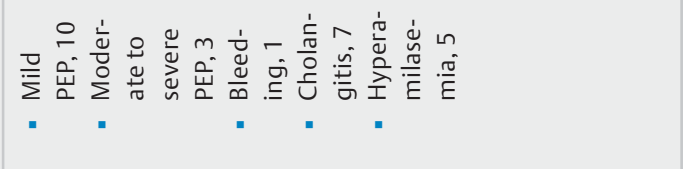 & 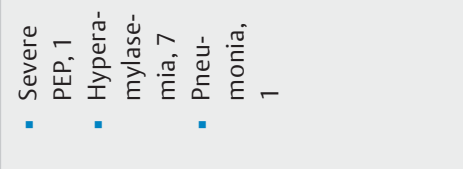 \\
\hline 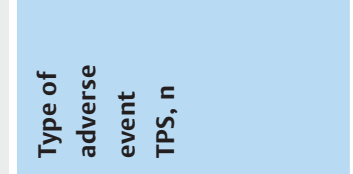 & 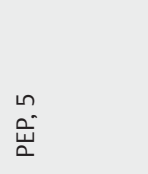 & 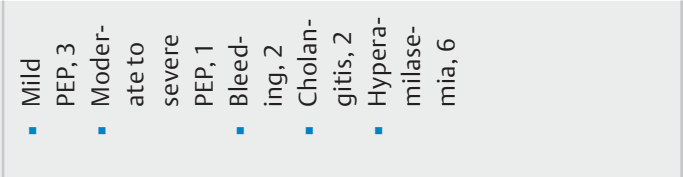 & 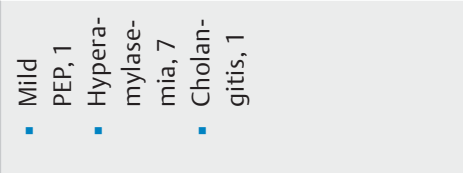 \\
\hline 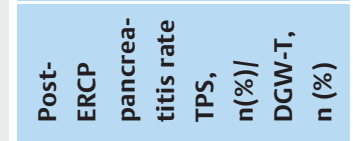 & 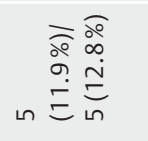 & 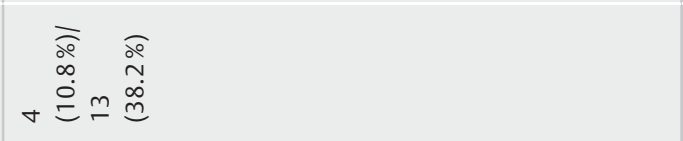 & 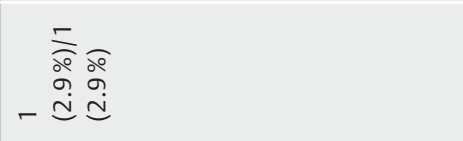 \\
\hline 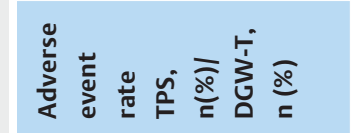 & 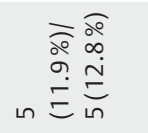 & 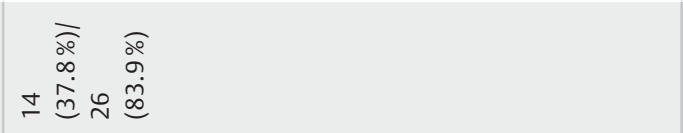 & 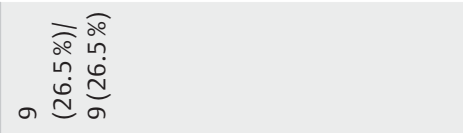 \\
\hline 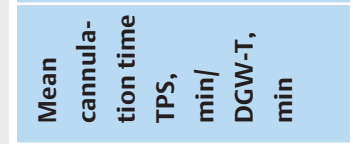 & 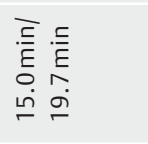 & 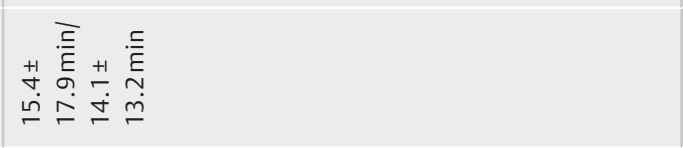 & 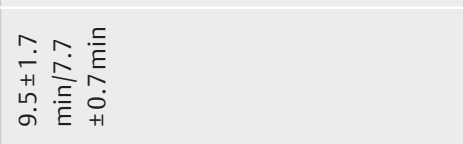 \\
\hline 冚忘总 & 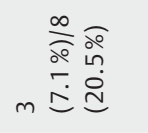 & 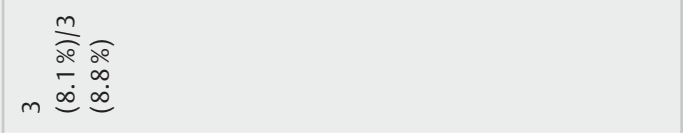 & 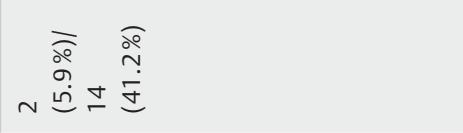 \\
\hline 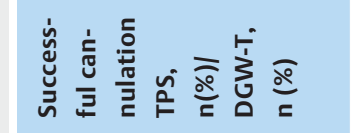 & 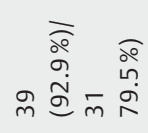 & 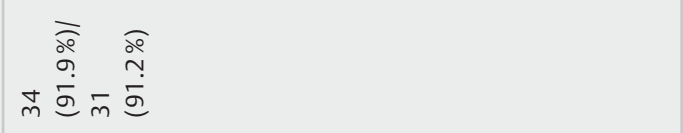 & 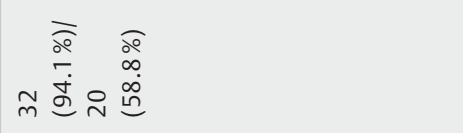 \\
\hline 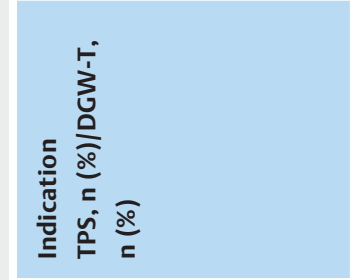 & $\Sigma$ & 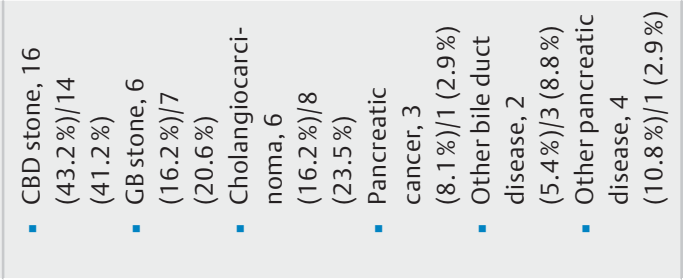 & 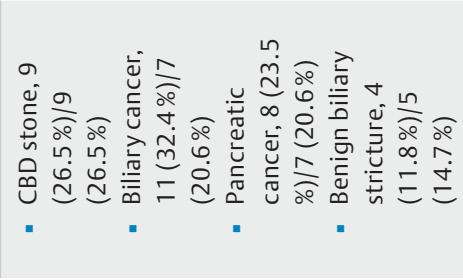 \\
\hline 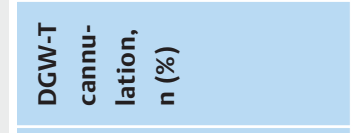 & 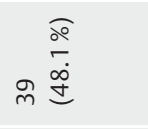 & 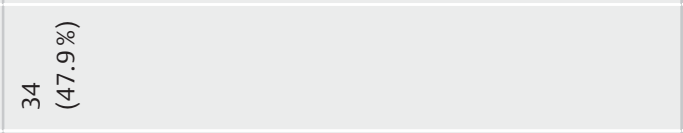 & 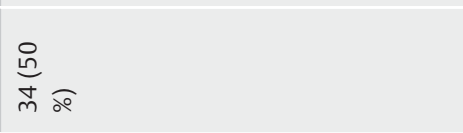 \\
\hline 啇 & チ & 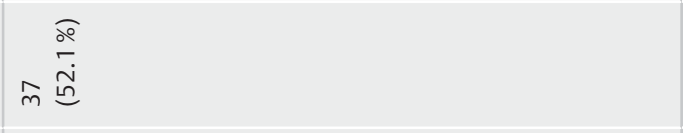 & 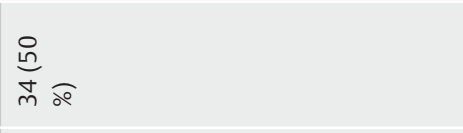 \\
\hline 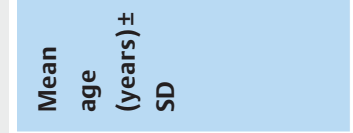 & $\bar{z}$ & 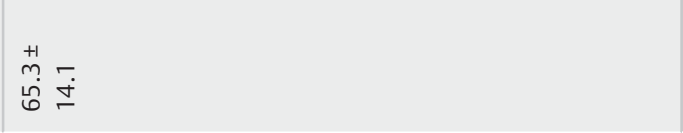 & 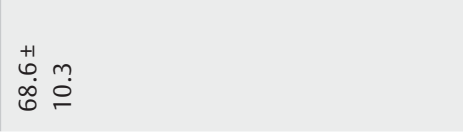 \\
\hline 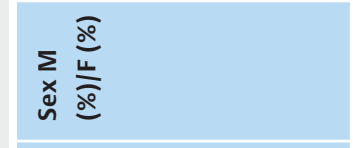 & $\Sigma$ & 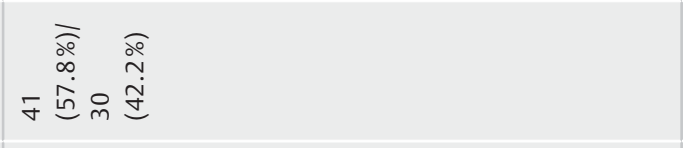 & 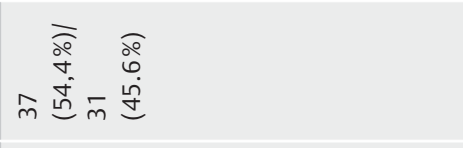 \\
\hline 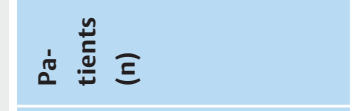 & $\bar{\infty}$ & 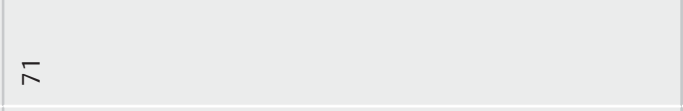 & $\infty$ \\
\hline 离咅 & 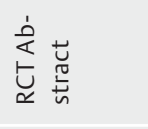 & $\stackrel{\longleftarrow}{\longleftarrow}$ & $\underset{\longleftarrow}{\longleftarrow}$ \\
\hline 站 & 岳 & 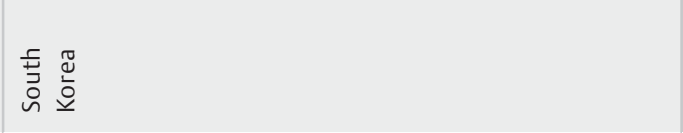 & 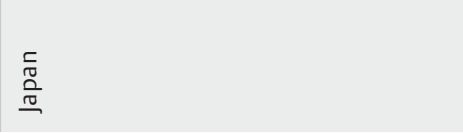 \\
\hline 字 & 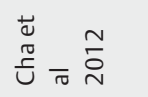 & $\begin{array}{l}\vec{\Delta} \\
\stackrel{n}{\circ}\end{array}$ & 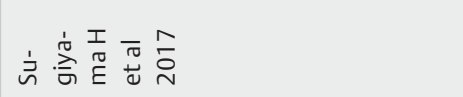 \\
\hline
\end{tabular}




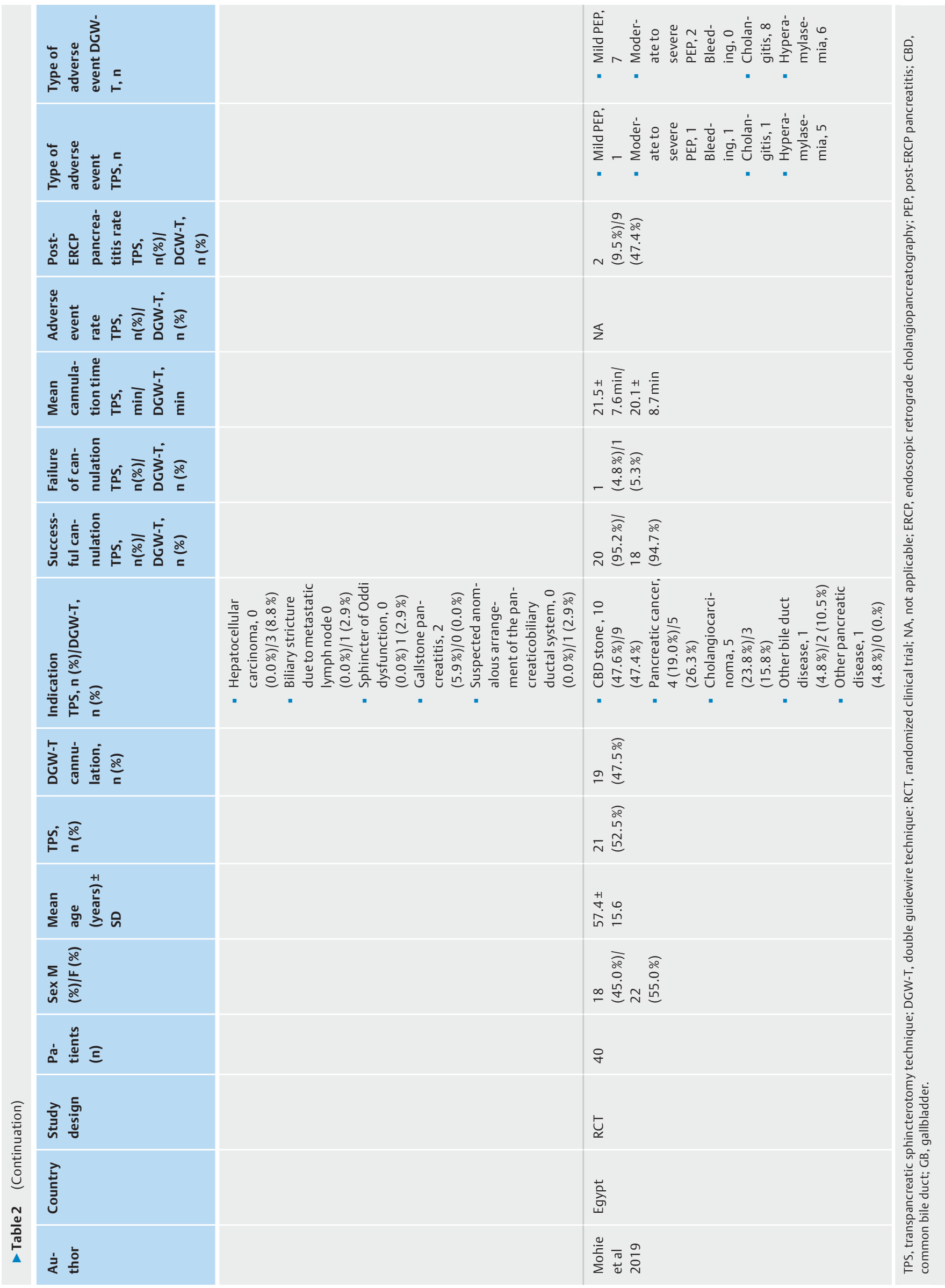




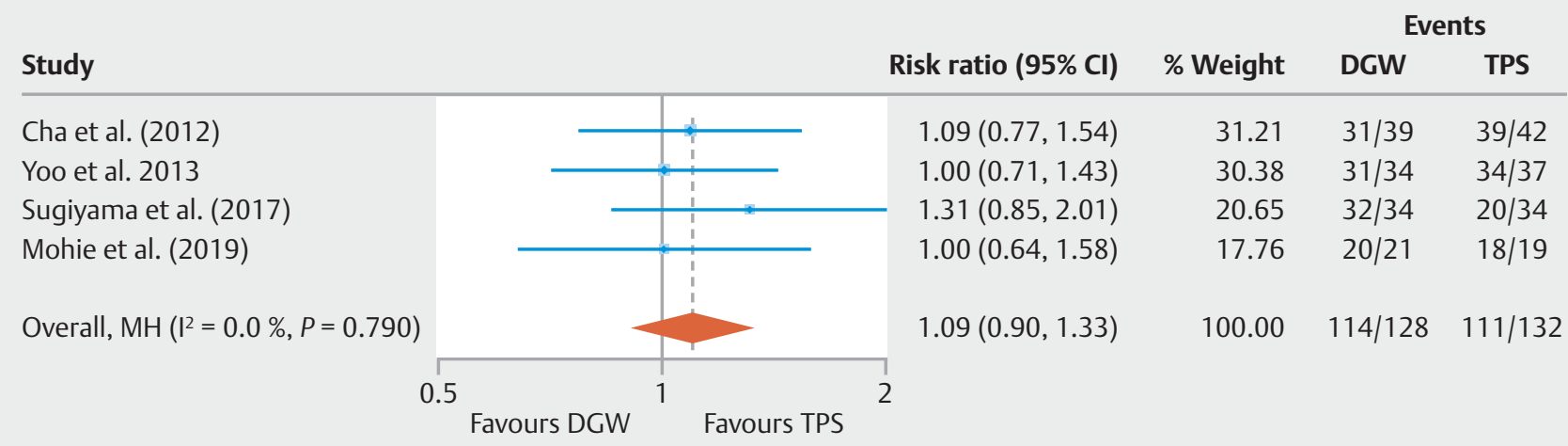

NOTE: Weights are from Mantel-Haenszel model

- Fig. 3 Forest plot of successful cannulation rate (TPS: $93.3 \%$ vs. DGW-T: $79.4 \%, \mathrm{RR}=1.09,95 \% \mathrm{Cl}[0.90-1.32]$ ).

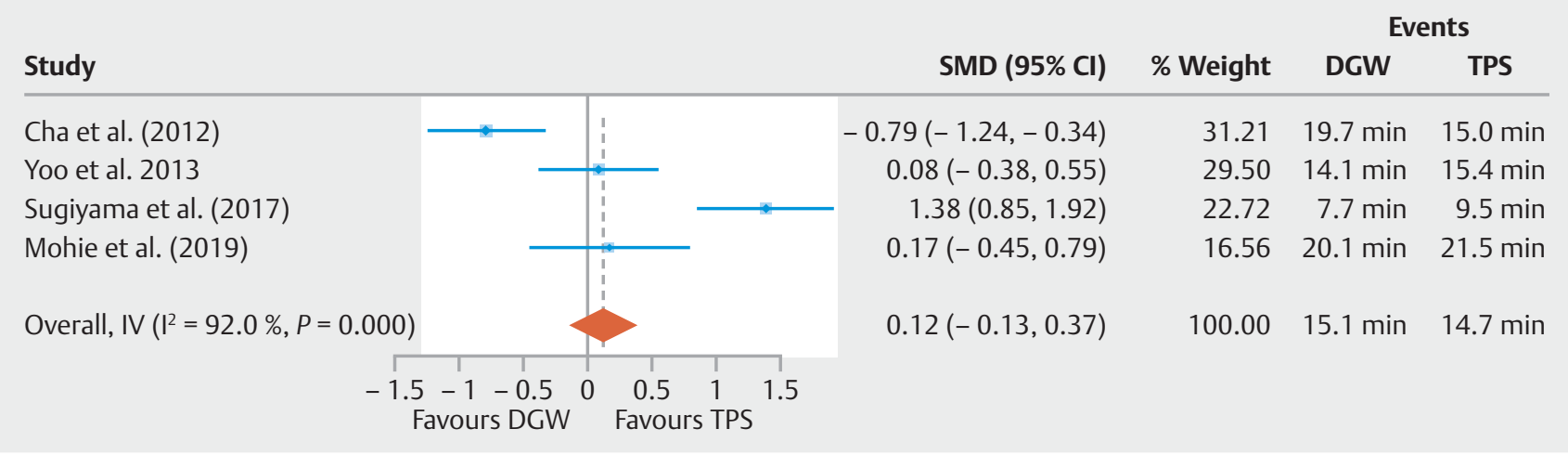

Fig. 4 Forest plot of mean cannulation time (TPS: $14.7 \pm 9.4 \mathrm{~min}$ vs DGW-T: $15.1 \pm 7.4 \mathrm{~min}, \mathrm{SMD}=0.121,95 \% \mathrm{Cl}[-0.13-0.37]$

\begin{tabular}{|c|c|c|c|c|c|c|}
\hline \multirow[b]{2}{*}{ Study } & & & \multirow[b]{2}{*}{ Risk ratio $(95 \% \mathrm{Cl})$} & \multirow[b]{2}{*}{ \% Weight } & \multicolumn{2}{|c|}{ Events } \\
\hline & & & & & DGW & TPS \\
\hline Cha et al. (2012) & $\begin{array}{l}1 \\
\end{array}$ & & $0.94(0.29,3.01)$ & 13.57 & $5 / 39$ & $5 / 42$ \\
\hline Yoo et al. 2013 & $\longrightarrow$ & - & $0.63(0.37,1.08)$ & 62.78 & $26 / 34$ & $14 / 37$ \\
\hline Sugiyama et al. (2017) & I & & $1.00(0.44,2.27)$ & 23.65 & $9 / 34$ & $9 / 34$ \\
\hline Overall, $\mathrm{MH}\left(\mathrm{I}^{2}=0.0 \%, P=0.606\right)$ & & & $0.76(0.50,1.15)$ & 100.00 & $40 / 107$ & $28 / 113$ \\
\hline 0.2 & 5 Favours DGW & 1 Favours TPS & 4 & & & \\
\hline
\end{tabular}

- Fig. 5 Forest plot of overall adverse events rate (TPS: $24.8 \%$ vs DGW-T: $37.4 \%, \mathrm{RR}=0.76,95 \% \mathrm{Cl}[0.50-1.15]$ )

and the AE rates. Second, the number of RCTs was small. However, they represented a suitable methodological design and a number of cases in each group adequate to result in a good statistical analysis.

We believe that our study is essential to eliminate the myth of the high number of complications and the fear of the main AEs of ERCP when using these techniques if conventional can- nulation cannot be performed. In addition, both techniques are useful if the CBD cannot be cannulated conventionally, as long as that is done by an endoscopist trained in these techniques. 


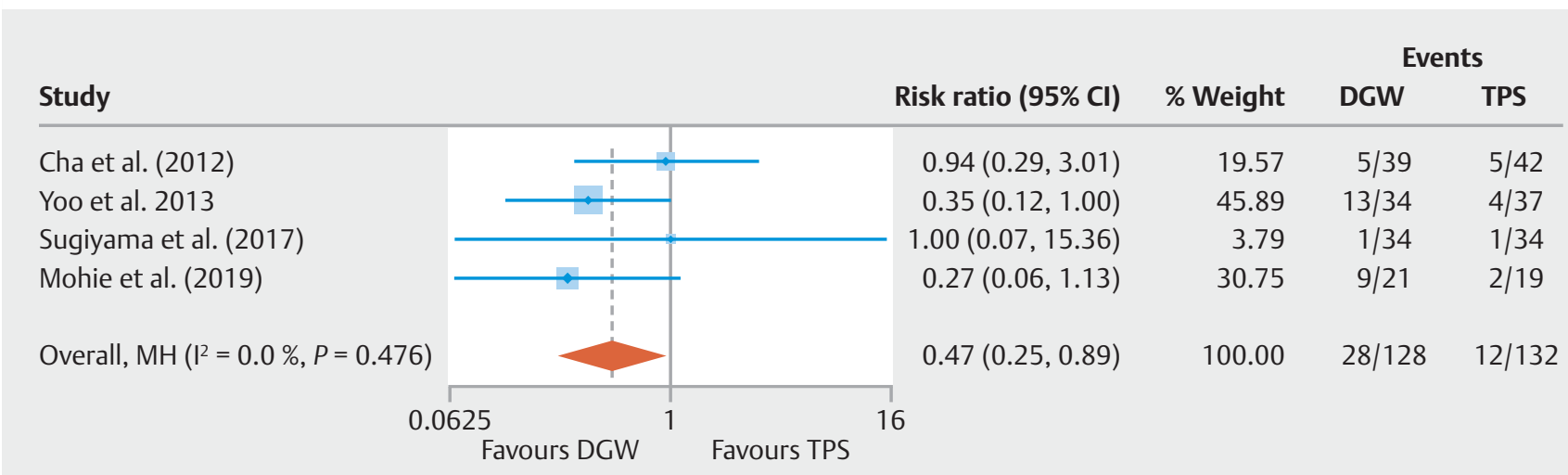

NOTE: Weights are from Mantel-Haenszel model

Fig. 6 Forest plot of post-ERCP pancreatitis rate (TPS: $8.9 \%$ vs DGW-T: $22.2 \%, \mathrm{P}=0.020, \mathrm{RR}=0.47,95 \% \mathrm{Cl}[0.25-0.89]$ )

\section{Conclusions}

TPS and DGW-T are two useful techniques in patients in whom cannulation is difficult. Our an analysis showed a high rate of successful cannulation with both TPS and DGW-T; however, the post-ERCP pancreatitis rate was higher with DGW-T than with TPS.

\section{Acknowledgements}

The authors thank Lourdes Carrera, Preventive Medicine and Public Health Unit, Universidad Nacional Mayor de San Marcos, Lima, Perú, Dr. Adrian Hernandez, Unidad de Revisiones Sistemáticas y Meta-análisis (URSIGET), Vicerrectorado de Investigación, Universidad San Ignacio de Loyola (USIL), Lima, Peru, Health Outcomes, Policy, and Evidence Synthesis (HOPES) Group, University of Connecticut School of Pharmacy, Storrs, Connecticut, United States of America, Dr. Alejandro Piscoya, Vicerrectorado de Investigación, Universidad San Ignacio de Loyola (USIL), Lima, Peru, and Hospital Guillermo Kaelin de La Fuente, Lima, Peru, who contributed to the statistical analysis of this manuscript.

\section{Competing interests}

The authors declare that they have no conflict of interest.

\section{References}

[1] DeBenedet A, Elmunzer B, McCarthy S et al. Intraprocedural quality in endoscopic retrograde cholangiopancreatography: a meta-analysis. Am J Gastroenterol 2013; 108: 1696-1704

[2] Testoni P, Mariani A, Aabakken L et al. Papillary cannulation and sphincterotomy techniques at ERCP: European Society of Gastrointestinal Endoscopy (ESGE) Clinical Guideline. Endoscopy 2016; 48: 657-683

[3] Liao W, Angsuwatcharakon P, Isayama $\mathrm{H}$ et al. International consensus recommendations for difficult biliary access. Gastrointest Endosc 2017; 85: 295-304
[4] Chandrasekhara V, Khashab MA, Muthusamy VR et al. ASGE Standards of Practice Committee. Adverse events associated with ERCP. Gastrointest Endosc 2017; 85: 32-47

[5] Nguyen-Tang T, Dumonceau J. Double-guidewire technique for difficult bile duct cannulation: why not insert a prophylactic pancreatic stent? Gastrointest Endosc 2010; 72: 466

[6] Dumonceau J, Deviere J, Cremer M. A new method of achieving deep cannulation of the common bile duct during endoscopic retrograde cholangiopancreatography. Endoscopy 1998; 30: S80

[7] Herreros de Tejada A, Calleja J, Díaz G et al. Double-guidewire technique for difficult bile duct cannulation: a multicenter randomized controlled trial. Gastrointest Endosc 2009; 70: 700-709

[8] Sasahira N, Kawakami H, Isayama $\mathrm{H}$ et al. Early use of double-guidewire technique to facilitate selective bile duct cannulation: the multicenter randomized controlled EDUCATION trial. Endoscopy 2015; 47: 421-429

[9] Goff JS. Common bile duct pre-cut sphincterotomy: transpancreatic sphincter approach. Gastrointest Endosc 1995; 41: 502-506

[10] Sakai Y, Tsuyuguchi T, Mikata R et al. Pancreatic duct guidewire-indwelling method for patients resistant to selective biliary cannulation and usefulness of pre-cut papillotomy following unsuccessful biliary cannulation with pancreatic duct guidewire-indwelling method. Hepatogastroenterology 2011; 58: 698-704

[11] Weber A, Roesch T, Pointner $S$ et al. Transpancreatic precut sphincterotomy for cannulation of inaccessible common bile duct: a safe and successful technique. Pancreas 2008; 36: 187-191

[12] Easterbrook PJ, Berlin JA, Gopalan R et al. Publication bias in clinical research. Lancet 1991; 337: 867-872

[13] Mantel N, Haenszel W. Statistical aspects of the analysis of datafrom retrospective studies of disease. J Natl Cancer Inst 1959; 22: 719-748

[14] Cha S, Kim S, Kim A et al. DGT vs TPS in patients with initial pd cannulation by chance; prospective randomized multi-center study. Gastrointest Endosc 2012; 75: AB141

[15] Yoo YW, Cha SW, Lee WC. Double guidewire technique vs transpancreatic precut sphincterotomy in difficult biliary cannulation. World J Gastroenterol 2013; 19: 108-114

[16] Sugiyama H, Tsuyuguchi T, Sakai Y et al. Transpancreatic precut papillotomy versus double-guidewire technique in difficult biliary cannulation: prospective randomized study. Endoscopy 2018; 50: 33-39

[17] Mohie E, Mohamed A, Al-Sisi M. Double guidewire technique versus transpancreatic sphincterotomy for difficult biliary cannulation. Egyptian J Hosp Med 2019; 74: 764-770 
[18] Huang L, Yu QS, Zhang Q et al. Comparison between double-guidewire technique and transpancreatic sphincterotomy technique for difficult biliary cannulation. Dig Endosc 2015; 27: 381-387

[19] Maeda S, Hayashi H, Hosokawa O et al. Prospective randomized pilot trial of selective biliary cannulation using pancreatic guidewire placement. Endoscopy 2003; 35: 721-724

[20] Herreros de Tejada A, Calleja JL, Díaz G et al. Double guidewire technique for difficult bile duct cannulation: a multicenter randomized, controlled trial. Gastrointest Endosc 2009; 70: 700-709
[21] Guzmán-Calderón E, Vera A, Díaz R et al. Efficacy and complications of double guidewire technique in biliary tract cannulation. Rev Gastroenterol Peru 2017; 37: 235-239

[22] Akashi R, Kiyozumi T, Jinnouchi K et al. Pancreatic sphincter precutting to gain selective access to the common bile duct: a series of 172 patients. Endoscopy 2004; 36: 405-410

[23] Kahaleh M, Tokar J, Mullick T et al. Prospective evaluation of pancreatic sphincterotomy as a precut technique for biliary cannulation. Clin Gastroenterol Hepatol 2004; 2: 971-977 